\title{
Medios de comunicación como agentes activos del conflicto: el caso de la Covid-19
}

\author{
Media as active agents of conflict: the case of the Covid-19
}

\author{
Diana Gómez Martínez \\ Universitat de Barcelona |Pg. de la Vall d'Hebron, 171, 08035 Barcelona \\ |https://orcid.org/000-0001-9006-2675 |dianagm1992@gmail.com
}

\section{Dra. Ángela A. Castrechini Trotta}

Universitat de Barcelona |Passeig de la Vall d'Hebron, 171, 08035 Barcelona |https://orcid.org/0000-0003-3241-5254 |acastrechini@ub.edu

Fechas | Recepción: 12/01/2021 | Aceptación: 19/05/2021

\section{Resumen}

La situación en la que se enmarca la actualidad está altamente condicionada por los efectos de la Covid-19. Debido a las consecuencias acarreadas por la epidemia y siendo los medios de comunicación masivos las entidades con mayor capacidad de difusión, la investigación que aquí se presenta se centra en analizar la cobertura mediática de las noticias relacionadas con la Covid-19. Para ello, se han escogido los diarios más leídos en la ciudad de Barcelona en la semana del 8 al 14 de febrero del 2020. El análisis pretende observar de manera sistemática, si estas notas de prensa han hecho un uso excesivo del miedo, la alarma o el belicismo como ya indican investigaciones previas, lo cual, derivaría en un fomento de la conflictividad entre los diferentes agentes sociales. Para ello, se ha utilizado la teoría del framing y así averiguar cómo se encuadra la muestra de noticias. Además, se ha utilizado el programa Atlas.ti para realizar un análisis cualitativo. Los resultados obtenidos muestran que el frame con más presencia fue el de "interés humano", seguido por los frames de "atribución de responsabilidades" y "económico". Los encuadres que tuvieron menor presencia fueron el de "moralidad" y el de "conflicto". No obstante, en el análisis

\begin{abstract}
The current situation is highly conditioned by the effects of the Covid-19. Due to the consequences brought about by the epidemic and being the mass media the entities with the greatest capacity of diffusion, the purpose of this research is focused on analyzing the media coverage of the news related to the Covid-19. For this purpose, the most widely read newspapers in the city of Barcelona have been chosen from the week of February 8 to 14, 2020. The analysis aims to systematically observe whether these press releases have made excessive use of fear, alarm or warmongering, as previous research indicated, which would lead to fostering conflict between the different social agents. The framing theory has been used to find out how the news sample is framed. In addition, the Atlas.ti program has been used to perform a qualitative analysis. The results obtained show that the frame with the highest presence was the "human interest" frame, followed by the "attribution of responsibilities" and "economic" frames. The frames with the lowest presence were "morality" and "conflict". However, in the qualitative analysis, a high use of narrative resources based on alarm, fear and war language was observed. It is likely that the observed tendency can be
\end{abstract}


cualitativo, se observó un alto uso de recursos narrativos basados en la alarma, el miedo y el lenguaje bélico. Es probable que la tendencia observada se pueda explicar por el momento temporal en que se recogió la muestra de noticias, es decir, antes del primer estado de alarma.

Palabras clave: Cobertura mediática Covid-19, prensa digital, framing, riesgo, conflicto social. explained by the timing of the news sample, this is before the first state of alarm.

Keywords: Media coverage Covid-19, digital press, framing, risk, social conflict.

\section{INTRODUCCIÓN}

Esta investigación trata de aportar información del enfoque desde la cual son presentadas las noticias de prensa sobre la Covid-19. La reciente pandemia ha derivado en cambios drásticos en cuanto a la organización de vida se refiere. A través de decretos políticos o de la misma deriva económica, se han producido profundos cambios en la vida de las personas en todos los niveles: sanitario, económico, social, educativo... Dadas estas alteraciones, nos preguntamos: ¿qué papel han desarrollado los medios de comunicación en la transmisión de los acontecimientos en relación a la epidemia? Al ser éstas las entidades con mayor capacidad de transmisión, se deposita en ellas la responsabilidad de transmitir la información necesaria para que la población pueda adoptar las medidas necesarias para paralizar la situación de crisis sanitaria. Sin embargo, y como muestran diversas investigaciones, los medios de comunicación suelen caer en el uso desmedido del alarmismo y del miedo cuando acontecen situaciones de emergencias sanitarias, favoreciendo así la ansiedad social, el miedo colectivo e incluso creando o alimentando el conflicto entre los diferentes agentes sociales implicados en la gestión de la crisis (Lewison, 2008; Camacho, 2009; Lorente, 2010; Monjas-Eleta y Gil-Torres, 2017; Costa-Sánchez y López-García, 2020). Nos preguntamos así, ¿qué rol han adquirido los medios de comunicación en la epidemia de la Covid-19? Concretamente en los días anteriores a que se decretara el estado de alarma en España, ¿cuál ha sido el tratamiento que se ha hecho de la temática? ¿Ha habido un mayor énfasis en el conflicto como encuadre de contenido? ¿Se han dado pautas de actuación claras y ajustadas a la realidad del momento analizado? ¿El enfoque utilizado ha ayudado a generar la alarma necesaria para lograr la implicación de la ciudadanía? Estas y otras preguntas se abordan en esta investigación.

El artículo parte de una revisión de la principal literatura acerca de la comunicación del riesgo y la comunicación en tiempos de crisis sanitaria pasando a través de investigaciones recientes y describiendo, por último, la teoría del encuadre o del framing. Esta teoría es utilizada en la metodología para analizar una muestra de 75 noticias que describimos en el apartado del método. Allí se explicita el procedimiento seguido para el análisis tras el cual se presentan la discusión de los resultados y las conclusiones de la investigación.

\section{REVISIÓN TEÓRICA}

\subsection{El papel de los medios de comunicación masivos}

Los medios de comunicación masivos (mass media) son canales por los cuales se distribuye información de actualidad considerada relevante, al mayor número posible de receptores o 
audiencia. Su papel es de suma relevancia ya que a través de ellos se genera el imaginario común acerca de un suceso. Para Quarantelli (2002), los medios de comunicación adquieren un papel principal al constituirse como actores implicados en la construcción social de la realidad y además conforman su propia definición de qué es una noticia, cómo se elabora y cómo se presenta, desmintiendo así la creencia de que las noticias son reflejadas como un fiel espejo de lo que acontece en la realidad. La función de los medios de comunicación es "inculcar a los individuos los valores, creencias y códigos de comportamiento que les harán integrarse en las estructuras institucionales de la sociedad" (Chomsky y Herman, 1990, p. 21), conformándose así los medios como agentes relevantes en la construcción social de la realidad (Busquets y Medina, 2013). Para Wolton (2004), la relación entre comunicación, información y conocimiento, tiene un papel central ya que la primera podría configurarse como impulsora de guerra e incomprensión entre individuos, derivando así en posibles conflictos sociales.

La comunicación en el caso de la Covid-19 tiene una gran importancia al ser una situación de crisis sanitaria global donde la atención de todo el público se centra en conocer la evolución de la situación y sus posibles consecuencias. Esto provoca fuertes movimientos en los medios de comunicación, que ofrecen un lugar central a la cobertura de este tipo de noticias tal y como indica la investigación elaborada por Westlund y Ghersetti (2015). Este estudio acerca de la relevancia de los medios en situaciones de crisis determina que eventos de crisis cercanos, generan un interés en alza por parte del público en cuanto a información relacionada con estos eventos y que, por lo tanto, se observa un aumento en el uso de los medios de comunicación tanto por los usuarios comunes de los medios como por los usuarios menos frecuentes.

Como investigaciones más actuales, tanto el trabajo de Casero-Ripollés (2020) llevado a cabo en Estados Unidos, como la investigación de Masip et al. (2020) en España, nos muestran un aumento significativo en el consumo de los medios de comunicación y noticias tras la aparición de la epidemia de la Covid-19, llegando en nuestro país a un $78 \%$ más de uso y consumo de estos medios que en momentos previos a la pandemia.

Altheide (2002), centrándose en el tipo de mensaje que tiene la cobertura mediática de los acontecimientos de peligro o crisis, afirma que el centro de estas coberturas se basa en el uso del miedo como proceso de control social, mientras que para Sandman (1994) el contenido se centra más en aspectos como el conflicto, los escándalos y el drama de las víctimas, hechos que envuelven todo el acontecimiento, más que centrarse en los riesgos técnicos.

Como vemos, la cobertura mediática de los medios de comunicación en una situación de pandemia juega un papel central. Son los responsables de transmitir una perspectiva más tranquilizadora o una visión más alarmista a través del enfoque que estos medios escojan para dar forma a la información que recibimos. En palabras de Camacho (2009), "Ios medios pueden tranquilizar a la gente, mientras ofrecen la información más completa posible sobre la magnitud de la enfermedad o, por el contrario, pueden activar en el público temores infundados que hagan que se incremente la alarma social" (p.5).

\subsection{La comunicación del riesgo y del miedo}

Antes de hablar de la comunicación del riesgo se ha de plantear la existencia de la sociedad del riesgo, sociedad que basa sus dinámicas en la existencia de factores de riesgo globalizados que amenazan nuestra forma de vida y que son consecuencia misma de las nuevas formas de producción. Esta es la teoría principal de Ulrich Beck (1998), que analiza cómo la misma ciencia 
y tecnología que ha mitigado problemas como el de la pobreza, ha generado simultáneamente nuevas dificultades que, traducidas en riesgos, más concretamente aquellos de carácter ecológico, son los que gobiernan nuestra sociedad actual.

Para Beck, los medios tienen una alta influencia social, cultural y política, y por ello, tienen la capacidad de repercutir en la opinión pública acerca de los riesgos del entorno, haciendo accesible a través de las noticias toda aquella información de riesgos cuando ésta no pueda ser percibida de forma sensorial por la población. Así, se promociona constantemente el riesgo que se enmarca en un tipo de comunicación que genera el imaginario social de los peligros: la comunicación del riesgo, la cual puede entenderse como:

Un proceso interactivo de intercambio de información y opinión entre los individuos, grupos e instituciones. Esto incluye múltiples mensajes acerca de la naturaleza de los riesgos y otros que no tratan directamente sobre el riesgo pero expresan algún tipo de preocupación, opinión o reacción a los contenidos sobre los riesgos o a los arreglos legales e institucionales de la gestión de los riesgos (National Research Council, 1989, p.21).

Se considera así que existe una bidireccionalidad de la comunicación, pero sin embargo, aunque consideremos este acto comunicativo como un proceso donde también participa el público, siguen siendo los medios los protagonistas de la comunicación eligiendo qué noticias resaltar y poseyendo la capacidad de expandir su mensaje a un alto número de personas.

Hasta aquí, los mass media son los encargados de transmitir a la población información sobre los riesgos existentes para así poner en marcha los mecanismos sociales y políticos necesarios para reducir el peligro, pero, ¿en qué medida los medios a través de esta comunicación generan un aumento del alarmismo y una exaltación del riesgo? ¿Y cómo contribuyen a construir conflictos entre los agentes sociales? Esto es lo que plantea Gil Calvo (2003), que considera que por la propia idiosincrasia de los medios, éstos cubrirán las noticias acerca de los riesgos amplificando sus posibles consecuencias y generando así alarma social. La relación entre el riesgo real y el percibido se ve en desequilibrio ya que los medios generan un aumento del último y se convierten así en "bombarderos pirómanos" que magnifican el riesgo creando mayores niveles de alarma social y cuyos efectos se convierten en sí mismos en riesgos y amenazas (Gil Calvo, 2003).

Sobre este mismo fenómeno de amplificación ya hablaron Kasperson et al. (1988), señalando que si se aplica esta amplificación al riesgo, se genera un proceso en el cual las respuestas mismas de los procesos comunicativos en cuanto a la experiencia social del riesgo, contribuyen a sus consecuencias generando una preocupación pública extraordinaria y determinando la magnitud percibida del riesgo (Kasperson et al., 1988).

A través de esta teoría se observa cómo el miedo es el ingrediente principal que caracteriza esta comunicación debido a su alto valor de persuasión que afecta al nivel emocional: "una apelación al miedo se puede definir como un mensaje persuasivo que despierta miedo representando una amenaza personal relevante y significativa, seguida de una descripción o recomendaciones factibles para disuadir la amenaza" (Stiff y Mongeau, 2003, p.148). Cuanta mayor es la dosis de miedo inyectada, mayor es la eficacia de la persuasión del mensaje (Boster y Mongeau, 1984). 
Establecemos así que el miedo es un componente esencial en la comunicación de riesgos, y que éste tiene una alta presencia en cuestiones de crisis sanitarias a las que hay que añadir el temor ya natural que puede generar en sí misma una epidemia de la magnitud de la Covid-19. Entonces nos preguntamos: ¿qué consecuencias tiene este tipo de comunicación basada en el miedo sobre el público en general? Sobre ello habla Camacho (2009) afirmando que "los medios son los principales responsables de la propagación de la cultura del miedo entre la población, porque amplifican las desgracias humanas y transmiten ese sentimiento de inseguridad que nos abruma" (p.3).

Por su parte Rey y Rincón (2008) afirman que el uso del recurso del miedo no responde únicamente a realidades que causen dicho temor, sino que son los propios medios los que generan este sentimiento en el público "explotando las historias de miedo, que son las generan audiencia, al mismo tiempo que nos hacen vivir en una situación de angustia permanente" (p.37).

Tenemos, por lo tanto, unos medios de comunicación que están en la primera línea dotando de información a la población, que por su propia idiosincrasia hacen uso del drama y del sensacionalismo en sus coberturas informativas, centrados en la comunicación de riesgos en momentos de crisis sanitarias y que hacen uso del miedo como herramienta persuasiva.

Juntando estos elementos debemos plantearnos si la manera de comunicar de los mass media hace un uso excesivo del temor como recurso narrativo y de prevención generando un clima exacerbado de ansiedad y miedo en el público. Por ello, planteamos a continuación algunas investigaciones que se han realizado acerca de las consecuencias que ha tenido la comunicación de los medios sobre el público en referencia a crisis sanitarias.

\subsection{Evidencias empíricas previas: comunicación y crisis sanitarias}

La crisis de la "gripe A" ha sido investigada desde el punto de vista de la comunicación de medios por varios estudios. Uno de ellos es el realizado por Idoia Camacho (2009), quien analizó el contenido del tratamiento informativo de las noticias en prensa durante la primera semana de la epidemia en España concluyendo que "se ha ofrecido una información demasiado alarmista y sensacionalista, que ha contribuido a extender el pánico y la angustia entre la población“ (p.4).

Al contrario, otro estudio realizado sobre el contenido del mismo tipo de noticias en Argentina, Estados Unidos y Venezuela llega a otras conclusiones diferentes, afirmando que pasada la primera fase, los medios se centraron en un tipo de cobertura más tranquilizadora, generando así un equilibrio entre los mensajes de alarma y contención (Hallin et al., 2020).

Investigaciones con el mismo objeto de estudio presentan conclusiones diferentes, aunque estas diferencias puedan venir por estar aplicadas en diferentes ámbitos geográficos y, por lo tanto, por diferencias culturales. Sin embargo, parece claro que ya sea desde una perspectiva catastrofista, o desde una visión más tranquilizadora, la influencia de los mass media en el público es clara. Esto demuestra el estudio realizado por Tauszik et al. (2012) también sobre el virus de la gripe A afirmando cómo los cambios en el tono y el lenguaje de la cobertura mediática de los periódicos, coinciden con el cambio de tono en las publicaciones en los blogs, confirmándose así la gran influencia que los medios tienen en la población. 
Investigaciones similares ofrecen resultados parecidos en cuanto al uso excesivamente alarmista y sensacionalista en las comunicaciones en relación con las crisis sanitarias como es el caso del síndrome agudo respiratorio (SARS) de 2003 (Lewison, 2008), el caso de la epidemia de Ébola en los Estados Unidos en el 2014 (Towers et al., 2015), o el análisis de esta misma epidemia de Ébola en España (González y Cambra, 2015; Monjas y Gil-Torres, 2017; Salvá y Jurado, 2015).

Como estudio de máxima novedad y relevancia para este trabajo, presentamos la investigación realizada por Costa-Sánchez y López-García (2020) en la que se observa la comunicación efectuada desde la cobertura de prensa durante las primeras etapas del Covid-19 en España. Concluyen los autores que, tal y como ha ocurrido en otras crisis sanitarias, se detecta un tono de alarmismo y un lenguaje bélico con el objetivo de despertar la urgencia en el comportamiento, pero que al mismo tiempo genera un sentimiento de miedo a nivel social. En la investigación ya mencionada anteriormente de Masip et al. (2020) en relación también a la Covid-19, constatan que "la mayoría de los ciudadanos afirma que los medios están tratando informativamente la pandemia de forma sensacionalista y generan alarma social innecesariamente" (p.8).

La presencia del alarmismo en la comunicación respecto a la Covid-19 queda patente en las investigaciones de Sabucedo, Alzate y Hur (2020) y Argiñano y Goikoetxea (2020), que muestran la alta presencia de metáforas relacionadas con la guerra en las comunicaciones relacionadas con la epidemia. Los autores también describen cómo estas metáforas afectan a la población en tanto que generan ansiedad, insolidaridad, identificación de un enemigo así como afectaciones negativas sobre los valores centrales del sistema político y democrático.

Para la detección de este tipo de comunicaciones alarmistas, proponemos la teoría del encuadre mediático desarrollada por Semetko y Valkenburg (2000).

\subsection{El concepto del framing y sus efectos}

Nacida desde una perspectiva psicológica y transitando la visión sociológica, llega de la mano de Tuchman (1978) la primera definición del framing en relación con el género periodístico definiéndolo como "una ventana cuyo marco delimita la realidad a la que se tiene acceso, limitando la percepción de otra realidad diferente y centrando la atención en ese fragmento específico" (citado en Ardèvol-Abreu, 2015, p.424)

Sin embargo, proponemos aquí la definición que hace Entman de la aplicación del framing como "la selección de algunos aspectos de la realidad recibida para hacerlos más destacados en un texto comunicativo, de tal manera que promuevan una definición de problema particular, interpretación causal, evaluación moral y / o recomendación de tratamiento para el ítem descrito" (Entman, 1993, p.52).

Según Tankard (2001), los mecanismos que los medios tienen para generar un tipo u otro de encuadre y transmitir una perspectiva concreta en el público son: enfocar el tema desde una perspectiva concreta, generar una agenda de atributos, hacer una selección de palabras o expresiones que confeccionen el discurso, dotar de énfasis a ciertos elementos y rasgos y elaborar una idea organizadora central que construya el relato informativo (citado en Igartua, Muñiz y Cheng, 2005). 
Respecto a la categorización de los frames noticiosos, De Vreese, Peter y Semetko (2001) se han propuesto, en primer lugar, una diferenciación entre los encuadres que tienen un enfoque genérico y un enfoque específico. Los genéricos (generic frames) son ampliamente aplicables a una variedad de temas y noticias así como ajustables en diferentes contextos culturales, mientras que los específicos (issue-specific) pertenecen a temas o eventos de noticias más concretos (De Vreese, Peter y Semetko, 2001).

Los mismos autores realizan una segunda distinción en cuanto a la generación de los encuadres basándose en metodología inductiva o deductiva. Desde el formato inductivo, se propone desgranar nuestra categoría de encuadres a la vez que realizamos la investigación, lo que supone poder detectar las muchas formas posibles en que el problema se puede enmarcar (Semetko y Valkenburg, 2000). Por el contrario, el formato deductivo supone, a partir de una serie de categorías previas predefinidas, clasificar los textos a analizar.

Desde el formato deductivo, Semetko y Valkenburg (2000) proponen una clasificación de frames genéricos que se divide en cinco categorías: conflicto, interés humano, consecuencias económicas, moralidad y atribución de responsabilidades.

Una vez descrito el frame y la categorización de éste, se ha de hacer referencia a la influencia que tiene sobre el público, el denominado framing effect (Muñiz, 2007). Para De Vreese (2005), las consecuencias del encuadre se observan a nivel social al tener influencia en la opinión pública, la política y la toma de decisiones colectivas. Existen varios estudios que demuestran cómo el tipo de encuadre seleccionado repercute en el impacto de las respuestas cognitivas que los sujetos tienen al ser expuestos a la noticia y en cómo éstos tienen influencia en las creencias, valores y actitudes que el público genera al enfrentarse a nuevos asuntos sociales (De Vreese, 2004; Igartua et al., 2008), encuadre que puede tener aún más relevancia en casos de pandemias o episodios catastróficos en los que el público tiene poca o nula experiencia cognitiva, teniendo un efecto aún más pronunciado (Shih, Wijaya y Brossard, 2008).

Dadas estas evidencias empíricas, entendemos que si comprendemos el framing desde el que se orienta una noticia, comprenderemos cómo la ciudadanía está generando su constructo en cuanto a la Covid-19.

Así pues, en este estudio se planteó como objetivo general, conocer cuál es el tratamiento mediático que ha realizado la prensa digital en cuanto a la comunicación de noticias relacionadas con la Covid-19 antes del decreto del primer estado de alarma. Concretamente se buscó identificar los encuadres mediáticos más utilizados por los medios analizados, conocer si las noticias analizadas se inscriben dentro del tipo de comunicación alarmista y explorar si se hace un uso excesivo del miedo como recurso narrativo en las noticias analizadas. Se partió de la hipótesis de que habría una gran presencia de noticias alarmistas y que uno de los frames predominantes sería el de conflicto.

\section{METODOLOGÍA}

La investigación se basa en el análisis de noticias de prensa en referencia al Covid-19 a partir de la teoría del framing utilizando el sistema de categorías propuesto por Semetko y Valkenburg (2000). Así pues, en el estudio se ha empleado una metodología de observación indirecta (Anguera, Portell, Chacón-Moscoso \& Sanduvete-Chaves, 2018) en tanto se basa en 
fuentes secundarias como son las noticias y, al mismo tiempo, se realiza desde el enfoque de los mixed methods (Anguera, Blanco-Villaseñor, Losada, Sánchez-Algarra \& Onwuegbuzie, 2018) ya que en la investigación se conjugan datos tanto de carácter cuantitativo, como cualitativo.

\subsection{Muestra}

Se han seleccionado los diarios más leídos en la ciudad de Barcelona según la "Enquesta de Serveis Municipals 2019" realizada por el Departament d'Estudis d'Opinió del Ayuntamiento de Barcelona. Según esta encuesta, los tres diarios más leídos son, por orden: La Vanguardia, El Periódico y El País y es sobre sus ediciones digitales de las que se ha extraído la muestra de noticias.

Para seleccionar el corpus de noticias se ha realizado una búsqueda en los tres periódicos desde el 1 de febrero del 2020, día posterior a que se conociera el primer caso de Covid-19 en España, hasta el 13 de marzo del mismo año, día anterior a que se decretase el estado de alarma en el país. La búsqueda ha sido acotada con todas aquellas piezas que contuvieran las palabras "coronavirus" y "Covid-19", seleccionando únicamente aquellas noticias que directamente tuvieran relación con la epidemia.

Se dejan fuera los reportajes, las crónicas, las entrevistas, los artículos de opinión y las cartas de los lectores ya que pertenecen a los géneros de opinión e interpretativo, y el foco de la investigación estaba en analizar cuál es el tratamiento que la prensa digital hace de las noticias sobre este tema. Tampoco se han seleccionado aquellas noticias que solo contengan fotos o vídeos ya que el análisis se realizará sobre el texto escrito. La muestra inicial estuvo constituida por 1300 noticias. La Figura 1 muestra la distribución de las noticias por semana y periódico en el período seleccionado.

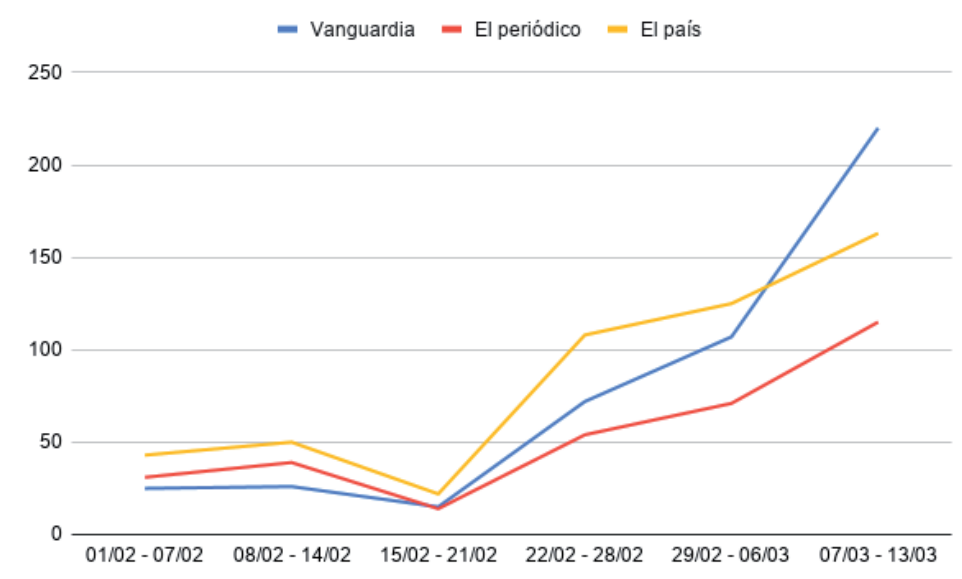

Figura 1. Distribución de noticias sobre la Covid-19 entre 1 Feb. y 13 Mar.2020 Fuente: elaboración propia.

Se puede apreciar cómo a partir de la cuarta semana hay un incremento constante de noticias acerca del Covid-19. Sin embargo, la semana elegida para realizar el análisis se basa en la idea de que en la comunicación del riesgo, las primeras semanas son de un alto interés ya que no existe conocimiento acerca de la gravedad de la enfermedad por parte de la población ni tampoco por los diferentes agentes sociales: científicos, políticos, medios, etc. De ahí radica la 
importancia de la comunicación en las primeras semanas de una crisis sanitaria ya que las comunicaciones tempranas previenen de un riesgo real o potencial para la salud, alertan a la población y evitan rumores e información distorsionada a pesar de que carezcan de toda la información necesaria (OMS, 2018). Por todo ello, se ha elegido la segunda con un total de 115 noticias, que además metodológicamente tiene la ventaja de ser una cifra manejable para poder hacer un análisis completo y exhaustivo.

Para delimitar aún más la muestra a analizar, del total de las 115 noticias, se han escogido analizar aquellas que cumplen con el criterio de contener entrada o lead, que encierra la información principal de la noticia, y cuerpo, que es donde se integran los detalles y que suele ocupar varios párrafos (García Perdomo y Gutiérrez Coba, 2011). Así, se descartan las noticias cortas (género "Breves") que no tienen ni el tamaño ni la estructura para realizar el análisis.

Adicionalmente, se han seleccionado las noticias de todas las secciones exceptuando las que se encuentren en Deporte o Cultura. Tras aplicar estos criterios, la muestra a analizar quedó finalmente constituida por un total de 75 noticias: 37 pertenecientes a El País, 21 de El Periódico y 17 de La Vanguardia.

\subsection{Instrumento de recogida de información}

Para el análisis se ha usado el sistema de categorías propuesto por Semetko y Valkenburg (2000), quienes establecen un conjunto de interrogantes para detectar los encuadres presentes en cada noticia. Estas cuestiones se muestran en su conjunto en la Tabla 1.

\section{Tabla 1}

Interrogantes para cada framing

\begin{tabular}{|c|c|}
\hline Framing & Interrogantes \\
\hline \multirow{4}{*}{$\begin{array}{l}\text { Atribución de } \\
\text { responsabilidades }^{1}\end{array}$} & $\begin{array}{l}\text { ¿La historia sugiere que algún nivel de gobierno tiene capacidad de aliviar el } \\
\text { problema? }\end{array}$ \\
\hline & ¿La historia sugiere que algún nivel de gobierno es responsable del problema? \\
\hline & ¿La historia sugiere soluciones al problema? \\
\hline & $\begin{array}{l}\text { ¿La historia sugiere que un individuo o grupo de personas de la sociedad es } \\
\text { responsable del problema? }\end{array}$ \\
\hline \multirow{4}{*}{ Interés humano } & ¿La historia muestra un rostro humano sobre el tema? \\
\hline & $\begin{array}{l}\text { ¿La historia emplea adjetivos o viñetas personales que generen sentimientos de } \\
\text { indignación, empatía, simpatía o compasión? }\end{array}$ \\
\hline & $\begin{array}{l}\text { ¿La historia enfatiza cómo las personas y grupos se ven afectados por el } \\
\text { tema/problema? }\end{array}$ \\
\hline & ¿La historia se refiere a la vida privada o personal de los actores? \\
\hline
\end{tabular}

1 En la obra los autores recogieron una quinta pregunta para este framing: ¿la historia sugiere que el problema requiere de una acción urgente? Sin embargo esta cuestión no cumplía con una carga del factor superior al 0.50 en su análisis factorial a través del método Varimax, lo que suponía que empírica y conceptualmente se encontraba más alejada de las cuestiones restantes. Es por ello que esta cuestión ha quedado excluida de la investigación 


\begin{tabular}{|l|l|}
\hline & $\begin{array}{l}\text { ¿La historia contiene información visual que podría generar sentimientos de } \\
\text { indignación, empatía, simpatía o compasión? }\end{array}$ \\
\hline Económico & $\begin{array}{l}\text { ¿Hay una mención de pérdidas o ganancias financieras ahora o en el futuro? } \\
\text { ¿Hay alguna mención de los costes o grado de gasto involucrado? } \\
\text { acción? }\end{array}$ \\
\hline Conflicto ${ }^{2}$ & $\begin{array}{l}\text { ¿La historia refleja desacuerdo entre partidos/individuos/grupos/países? } \\
\text { ¿Un partido/individuo/grupo/país reprocha a otro? }\end{array}$ \\
\hline ¿La historia se refiere a dos o más partes del tema o problema?
\end{tabular}

Fuente: adaptado de Semetko y Valkenburg (2000).

Estos interrogantes han sido aplicados a través de la creación de un Google Form como instrumento de recogida de información para cada uno de los tipos de frame.

\subsection{Procedimiento de análisis de las noticias}

Recogida la muestra y elaborado el cuestionario, la investigadora principal procedió a leer cada noticia para contestar las preguntas contenidas en el cuestionario. Esto se hizo para cada una de las 75 noticias. La co-investigadora hizo lo mismo con un 10\% de las noticias seleccionadas al azar, y se obtuvo un grado de confiabilidad entre jueces del 75,69\%. El método para extraer el porcentaje ha sido a través de la fórmula propuesta por Miles y Huberman (1994): número total de acuerdos / número total de acuerdos + desacuerdos. De esta fracción se ha extraído el porcentaje que es el que corresponde al $75,69 \%$ obtenido. Según los mismos autores, se requiere un mínimo de un $75 \%$ de acuerdo para demostrar que la confiabilidad entre jueces es suficiente para que el estudio sea riguroso.

Una vez finalizada la primera fase del análisis, se introdujeron todas las noticias en el Atlas.ti (versión 8.0) para explorar los datos con una aproximación cualitativa. En primer lugar, se procedió a agrupar las noticias por frame generando nubes de palabras para cada uno de ellos. Con el fin de generar nubes más "limpias" se eliminaron de manera automática algunos

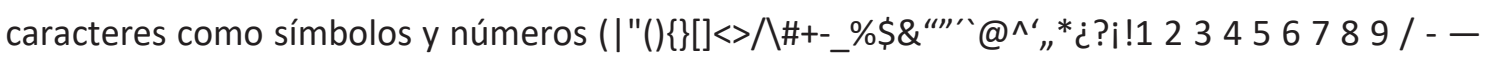
- (c « »), también de manera manual, preposiciones (de, del, que, no, se, al, con, ya hasta según, etc.) y alguna fecha.

En segundo lugar, se procedió a realizar un análisis cualitativo sólo de aquellas noticias que habían sido categorizadas en el frame de "conflicto". Se procedió a releer estas noticias, identificando los extractos que reflejaban las diferentes categorías de análisis (los cinco frames

2 En la obra los autores recogieron una cuarta pregunta para este framing: ¿la historia se refiere a ganadores o perdedores? Sin embargo esta cuestión no cumplía con una carga del factor superior al 0.50 en su análisis factorial a través del método Varimax, lo que suponía que empírica y conceptualmente se encontraba más alejada de las cuestiones restantes. Es por ello que esta cuestión ha quedado excluida de la investigación. 
de Valkenburg y Semetko), así como las subcategorías (o preguntas específicas a las que hacían referencia) (recogidas en la tabla 1). Este análisis permitió detectar aquellas citas en las que se hacía uso del miedo y del lenguaje bélico como recurso narrativo, así como citas que alertaban a la población, generando un cierto estado de alarma (ver Tabla 2). Una vez realizada esta categorización, se procedió a generar la red de relaciones para cada frame dentro de la categoría general de "conflicto", es decir, la red entre códigos pertenecientes a una misma categoría y su conexión con los códigos co-concurrentes. Se seleccionarán algunos datos para ser expuestos en el apartado de resultados.

Tabla 2

Definición de categorías de análisis

\begin{tabular}{|c|l|}
\hline Categoría & \multicolumn{1}{c|}{ Definición } \\
\hline Alarma & $\begin{array}{l}\text { Incluye aquellas noticias en las que se usan palabras } \\
\text { como alarma, alerta, amenaza, emergencia y cuando } \\
\text { se aportan datos numéricos que indican aumento de } \\
\text { los contagios o muertes }\end{array}$ \\
\hline Guerra & $\begin{array}{l}\text { Incluye aquellas noticias en las que se usan palabras } \\
\text { como luchar, enemigo, batalla, arma, vencer, etc. }\end{array}$ \\
\hline Miedo & $\begin{array}{l}\text { Incluye noticias en las que se usan palabras como } \\
\text { miedo, temor, desconfianza, etc }\end{array}$ \\
\hline
\end{tabular}

Fuente: elaboración propia.

\section{RESULTADOS}

\subsection{Análisis del frame}

A continuación, se presentan los resultados obtenidos tras la aplicación de las preguntas de cada encuadre a cada una de las 75 noticias (ver Figura 2): 


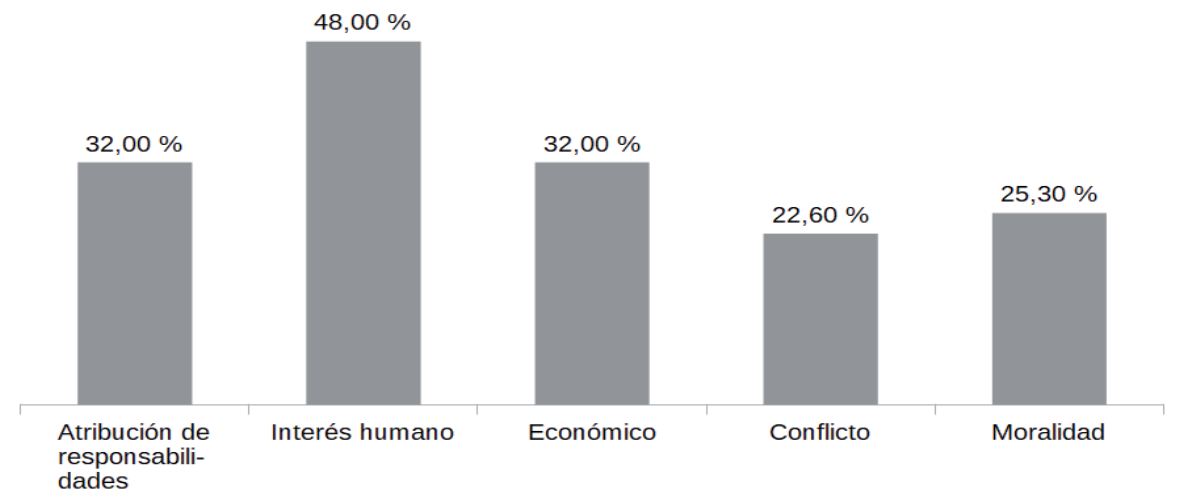

Figura 2. Distribución porcentual de los frames con respecto al total de noticias.

Fuente: elaboración propia.

Se observa que el frame con más presencia es el de "interés humano", el cual se pudo encontrar en el $48 \%$ de las 75 noticias, seguido por los frames de "atribución de responsabilidades" y "económico", con un 32\% cada uno. Los encuadres que tienen menos presencia son el de "moralidad" $(25,30 \%)$ y, en último lugar, el de "conflicto" $(22,60 \%)$.

Se ha de señalar que algunas de las noticias analizadas pueden haber dado positivo en más de un encuadre simultáneamente ya que las categorías no son mutuamente excluyentes. Del mismo modo, otras de las noticias no han respondido positivamente a ninguna de las preguntas de los cinco encuadres, no siendo ubicadas de esa manera en ninguno de ellos.

A continuación, se presenta un análisis específico para cada uno de los cinco encuadre:

\subsubsection{Framing de "atribución de responsabilidades"}

Hasta un $79,10 \%$ de estas noticias dentro de este framing sugieren que algún nivel del gobierno es responsable del problema del que trata la noticia (ver Figura 3).

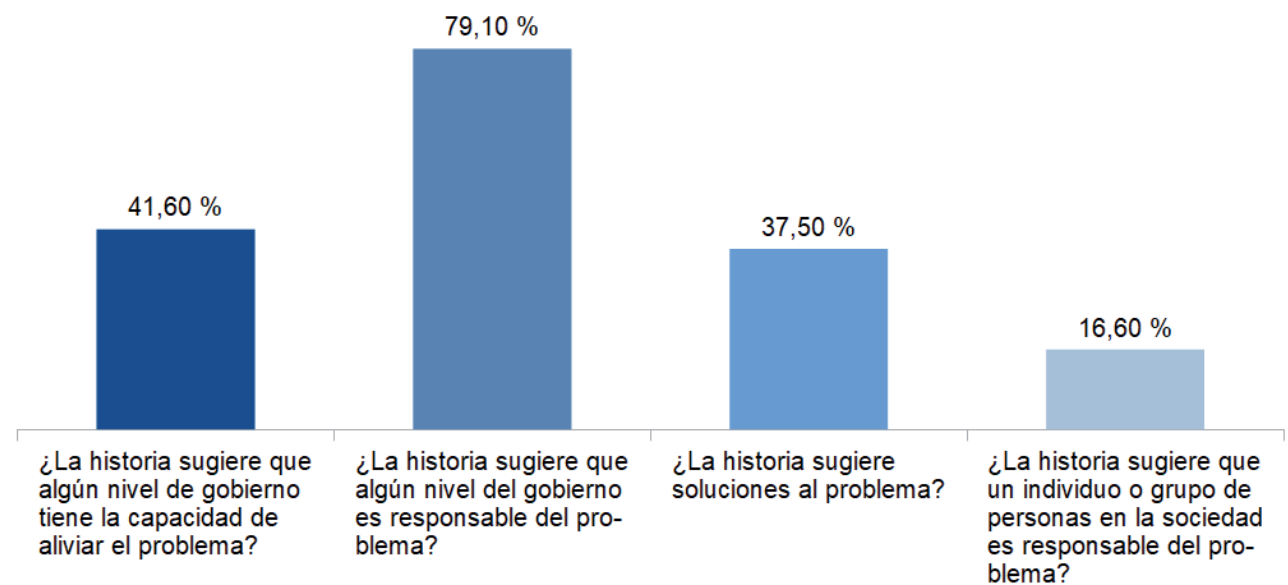

Figura 3. Distribución de noticias dentro del framing "atribución de responsabilidad" en función del porcentaje con respuesta positiva a cada una de las cuestiones.

Fuente: elaboración propia.

Más concretamente se responsabiliza en gran medida a las instituciones gubernamentales de China y su gobierno provincial de Hubei por la gestión, opacidad, censura y falta de libertad de expresión en el país según los diarios analizados. Un ejemplo de ello es el siguiente: 
"La pésima gestión de las autoridades de Wuhan durante la aparición del coronavirus puede pasarle factura al Gobierno de Pekín" (LV-11 Feb. 2020-1).

\subsubsection{Framing de "interés humano"}

De las 75 noticias analizadas, un $48 \%$ de ellas han contestado positivamente a alguna de las cuestiones pertenecientes a este encuadre, convirtiéndose así en el frame más utilizado de todos. De este $48 \%$ en la Figura 4 se muestra qué porcentaje responden "sí" a cada una de las cuestiones formuladas.

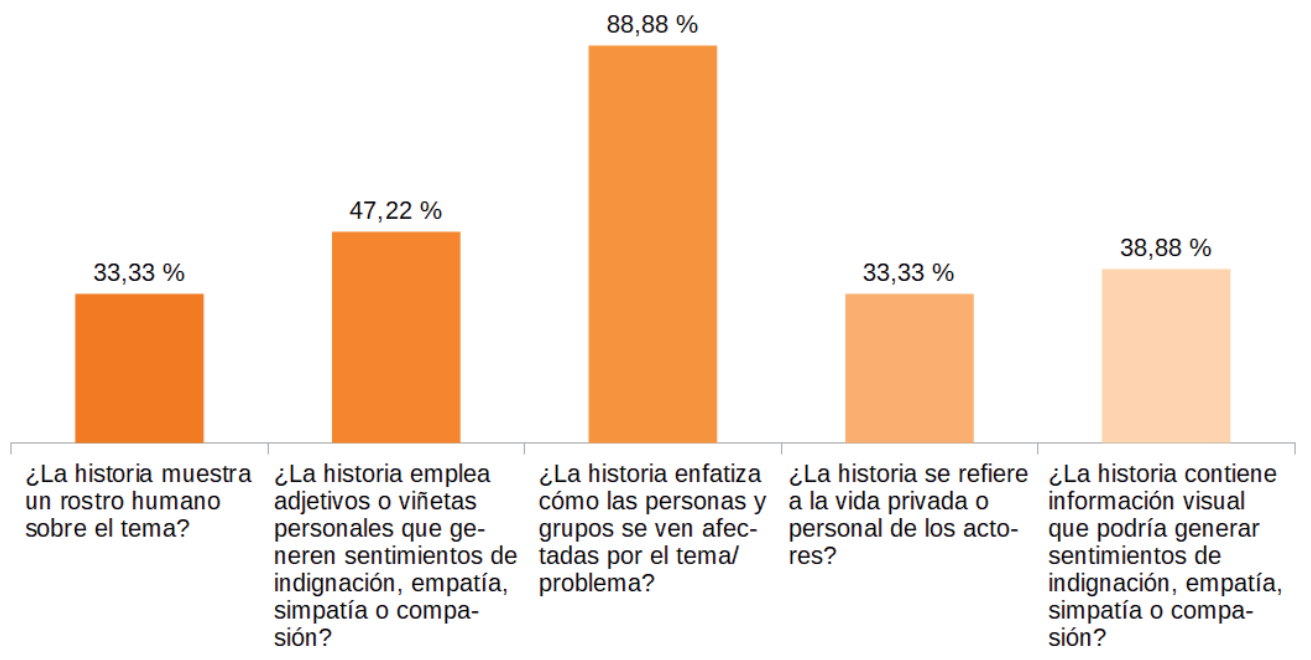

Figura 4. Distribución de noticias dentro del framing "interés humano" en función del porcentaje con respuesta positiva a cada una de las cuestiones

Fuente: elaboración propia.

La cuestión que tiene más presencia con un 88,88\%, es aquella que pregunta acerca del énfasis de la noticia en las consecuencias del problema en cuestión para las personas o grupos. Un extracto ilustrativo es el siguiente:

"Creen que ella se infectó cuando compraba verduras. Tuvieron que esperar más de doce días para el ingreso. Llamaron a la línea directa especial de la alcaldía. Llamaron a los líderes provinciales. Nada. No había camas disponibles en ninguna parte. "Se supone que tienes que informar al comité de barrio, y ellos reportan tu caso. Te dicen que esperes en cuarentena en casa y te vayas controlando los síntomas. Ellos no pueden conseguir una plaza. Hay mucha gente que ha muerto así, esperando", se lamenta Zhang." (PAís-12 Feb. 2020-4).

La segunda cuestión que más aparece con un 47,22\% de presencia es aquella en la que se muestran adjetivos que generan algún tipo de emoción hacia los actores de la noticia por parte del lector, seguida de aquella en la que menciona la aparición de algún tipo de información visual que también genere sentimientos concretos hacia los actores de la noticia con un $38,88 \%$. Un ejemplo es el siguiente: 


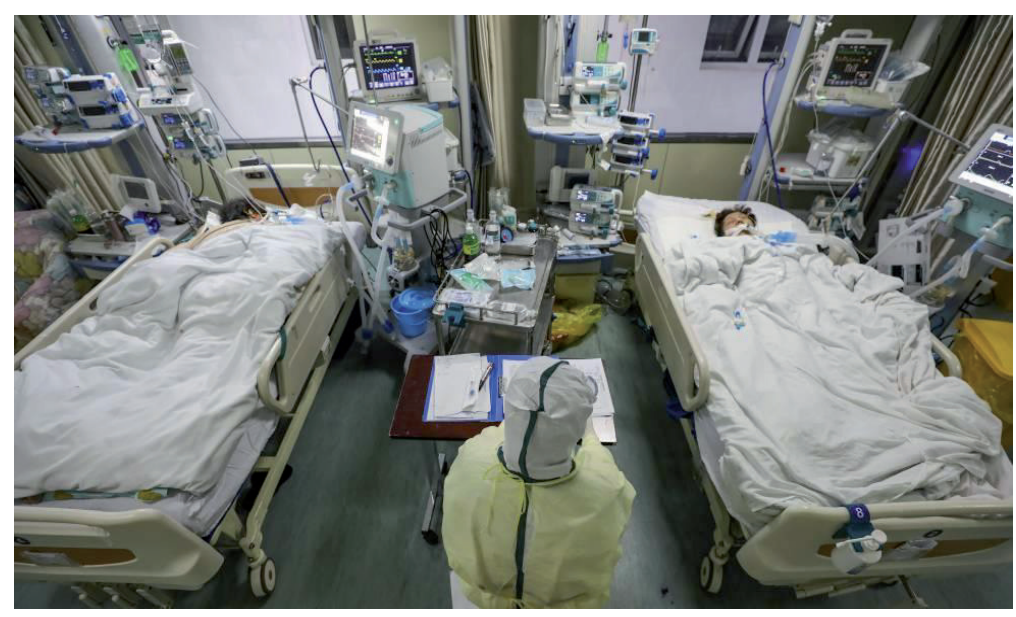

Figura 5. Afectados por el coronavirus ingresados en un hospital de Wuhan, este jueves. Fuente: El País 09.02.2022.

\subsubsection{Framing "conflicto"}

Este encuadre es el menos utilizado de entre todos los frames con solo un $22,60 \%$ de apariciones y se puede ver cómo se distribuye el porcentaje según las preguntas en la Figura 6.

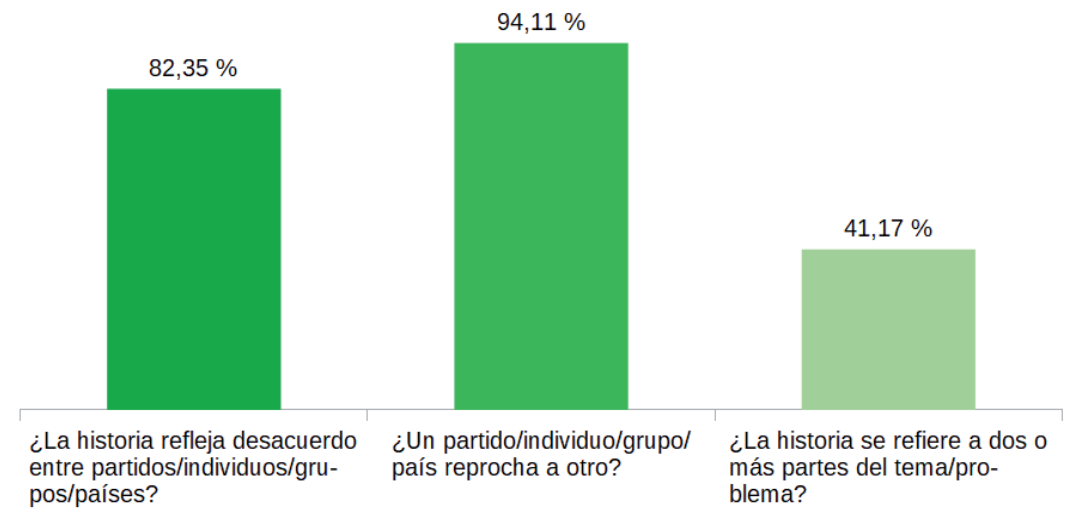

Figura 6. Distribución de noticias dentro del framing "conflicto" en función del porcentaje con respuesta positiva a cada una de las cuestiones

Fuente: elaboración propia.

El 94,11\% de las 17 noticias que pertenecen al encuadre "conflicto" muestra cómo un actor realiza un reproche a otro por alguna cuestión relacionada con la epidemia. Un ejemplo de ello es el siguiente extracto:

"La decisión de imponer cuarentenas draconianas, extender las vacaciones del Año Nuevo chino y el consiguiente cierre de fábricas y rutas de transporte van a reducir un punto el PIB chino este año, según el consenso de los analistas (...) La calidad de la gobernanza china, incapaz de desterrar de su territorio enfermedades propias de un país emergente, se ha visto cuestionada. "Nunca hemos vivido en un mundo en el que una de las potencias dominantes tuviera un perfil de riesgo tan elevado", subraya Bremmer en su carta de esta semana" (PAís08 Feb. 2020-2). 
La cuestión referida a si la historia muestra un desacuerdo entre dos partes está presente en el $82,35 \%$ de las noticias de este encuadre.

\section{Framing "moralidad"}

Este encuadre es el segundo con menor presencia con un 25,30\% (ver Figura 7).

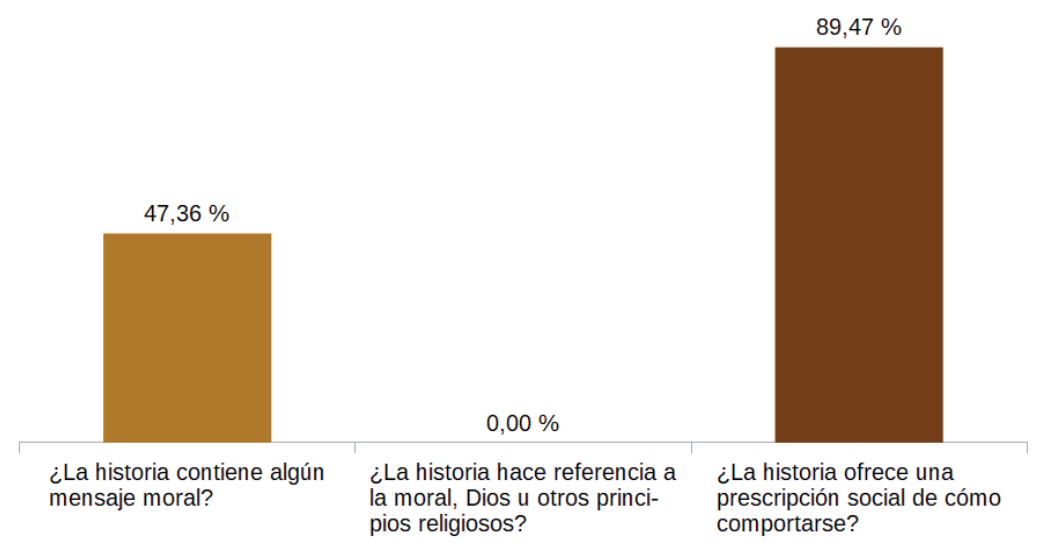

positiva a cada una de las cuestiones

Fuente: elaboración propia. Figura 7. Distribución de noticias dentro del framing "moralidad" en función del porcentaje con respuesta

La cuestión con mayor presencia es aquella que contiene algún tipo de prescripción social acerca de cómo comportarse ante la situación. Un ejemplo de ello es el siguiente:

“Antonio Cano Vindel (...) considera “lógico" que la alerta por el coronavirus "genere cierto temor" por las incógnitas sobre esta enfermedad. Pero apunta que si los ciudadanos gestionaran la situación "recurriendo a información científica, razonamientos lógicos o contrastando la realidad con otras experiencias (habla de las muertes por la gripe común) llegarían a la conclusión de que en estos momentos no hay justificación para un miedo intenso irracional"'” (LV-14 Feb. 2020-1).

\subsubsection{Framing "económico"}

En este encuadre, el porcentaje de las 75 noticias que han contestado positivamente a alguno de los interrogantes es un $32 \%$ sobre el total. El porcentaje de cada una de las preguntas que responden "sí" a las cuestiones formuladas se muestra en la Figura 8. 


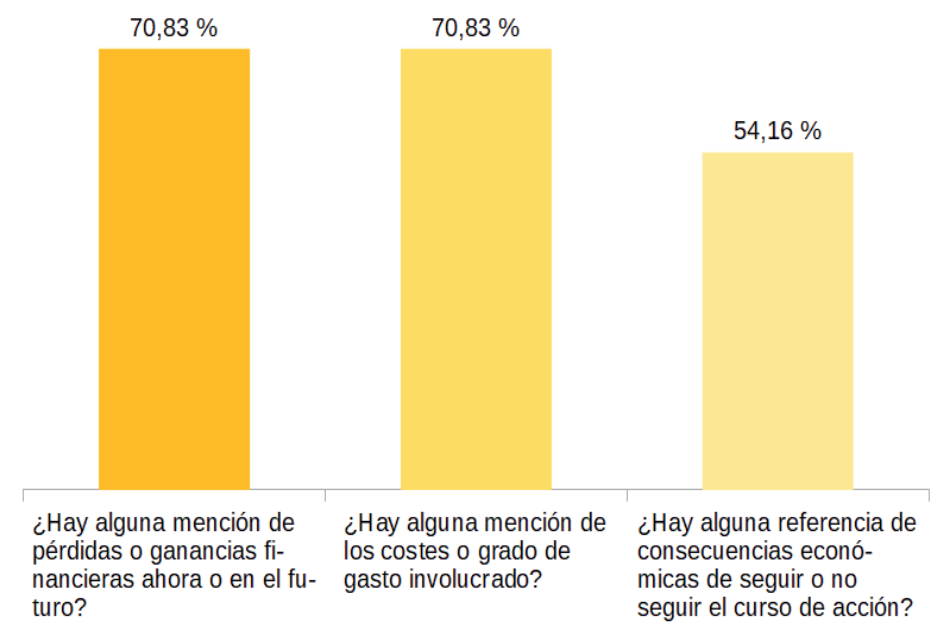

Figura 8. Distribución de noticias dentro del framing "económico" en función del porcentaje con respuesta positiva a cada una de las cuestiones

Fuente: elaboración propia.

En este encuadre en el que solo hay tres cuestiones, dos de ellas encabezan su presencia a la par con un porcentaje del $70,83 \%$. Se refieren a la mención de pérdidas o ganancias financieras, así como a costes o gastos involucrados en el acontecimiento. A continuación se muestra un extracto que responde positivamente a ambas interrogantes:

"Y las consecuencias de la cancelación tendrán un coste millonario. Solo el presupuesto de los participantes (alquiler de pabellones, viajes, hoteles, dietas, etcétera) asciende a 500 millones de euros (...) A esa factura hay que sumar las incontables pérdidas de ingresos de la ciudad de Barcelona, de la que se quejaban ya este miércoles los hoteleros." (PAís-13 Feb. 2020-6)

La tercera cuestión referida a consecuencias derivadas de seguir o no seguir un determinado curso de acción, es la que tiene menos presencia con un $54,16 \%$ de respuestas positivas.

\subsection{Nubes de palabras}

Se presentan a continuación las nubes de palabras generadas a través del programa Atlas.ti para los encuadres de "conflicto" y "atribución de responsabilidades" al ser los más relevantes para el objetivo de esta investigación.

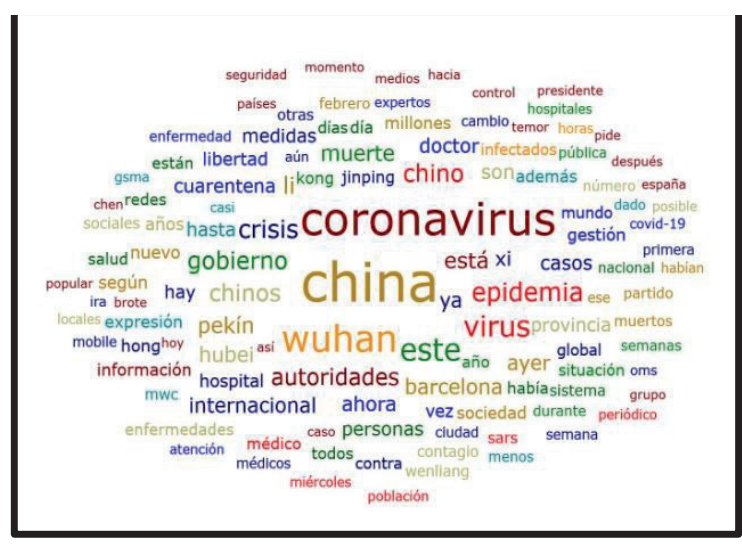

Figura 9: Nube "Conflicto"

Fuente: elaboración propia. 


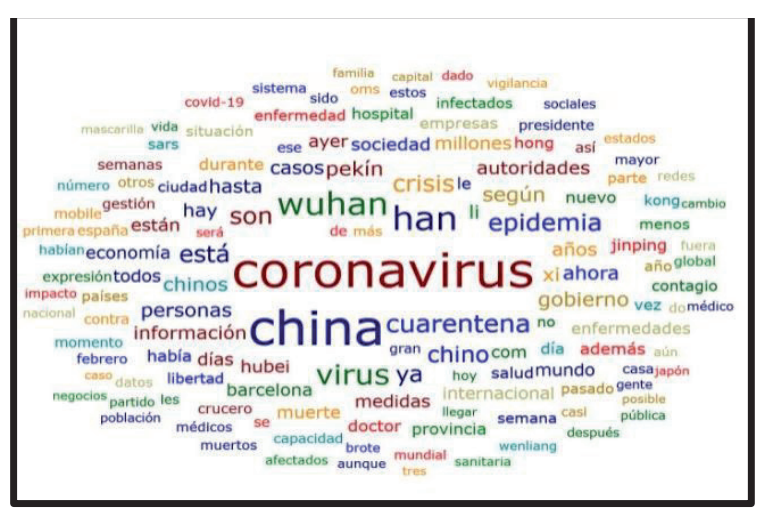

Figura 10. Nube "Atribución de responsabilidades"

Fuente: elaboración propia.

Se ve claramente cómo las palabras que más se repiten en ambos encuadres son: coronavirus, China, Wuhan y sus derivaciones semánticas.

A continuación se muestran 10 de las palabras que más destacan para cada uno de los frames además de las ya comentadas.

- Frame "conflicto": epidemia, virus, gobierno, crisis, autoridades, muerte, cuarentena, gestión, doctor y libertad.

- Frame "atribución de responsabilidades": cuarentena, epidemia, virus, personas, información, gobierno, crisis, autoridades, libertad y medidas.

En cuanto al objetivo de discernir si las notas de prensa analizadas hacen uso de un lenguaje alarmista, usan el recurso del miedo o la metáfora bélica, se observa a través del análisis del Atlas.ti en las nubes de palabras más utilizadas para cada frame, que no se da específicamente la presencia desmedida de vocabulario referido al miedo, la alarma o la guerra. Aunque sí podemos comentar que los términos más usados dependiendo del encuadre, se corresponden perfectamente con el frame utilizado. Por ejemplo, en el frame "económico" se utiliza con mucha frecuencia las palabras "empresas", "impacto", "millones", o la propia palabra "económico", teniendo por lo tanto sentido el uso de estos términos en cada uno de los encuadres analizados.

\subsection{Red de relaciones}

Se ha procedido a extraer las redes de relaciones de los 5 frames, sus preguntas específicas y adicionalmente las categorías de "alarma", "guerra" y "miedo" dentro de aquellas noticias que se han catalogado dentro del encuadre "conflicto". A continuación, se muestran exclusivamente las redes generadas para "conflicto", "alarma", "guerra" y "miedo". Las conclusiones de los resultados de redes se muestran en el apartado 6 "Discusión y conclusiones". 


\subsubsection{Red de relaciones "conflicto"}

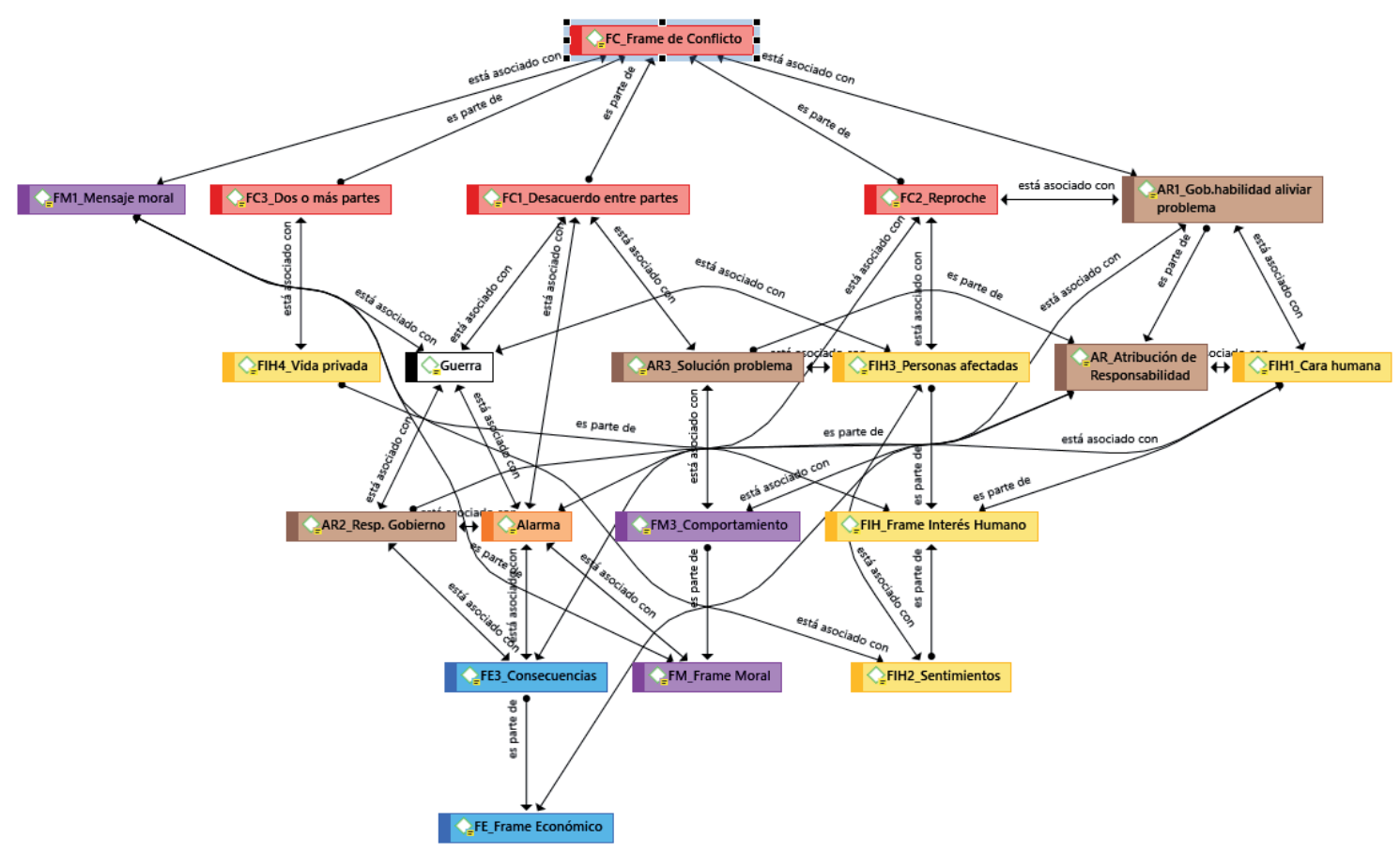

Figura 11. Red de relaciones del frame "conflicto" Fuente: elaboración propia.

Observando esta red, vemos cómo dentro del frame general de conflicto (FC)3, sus preguntas específicas tienen una correlación con las categorías de "guerra" y "alarma", así como con las cuestiones referidas de "atribución de responsabilidades" e "interés humano" sobre todo. 


\subsubsection{Red de relaciones "alarma"}

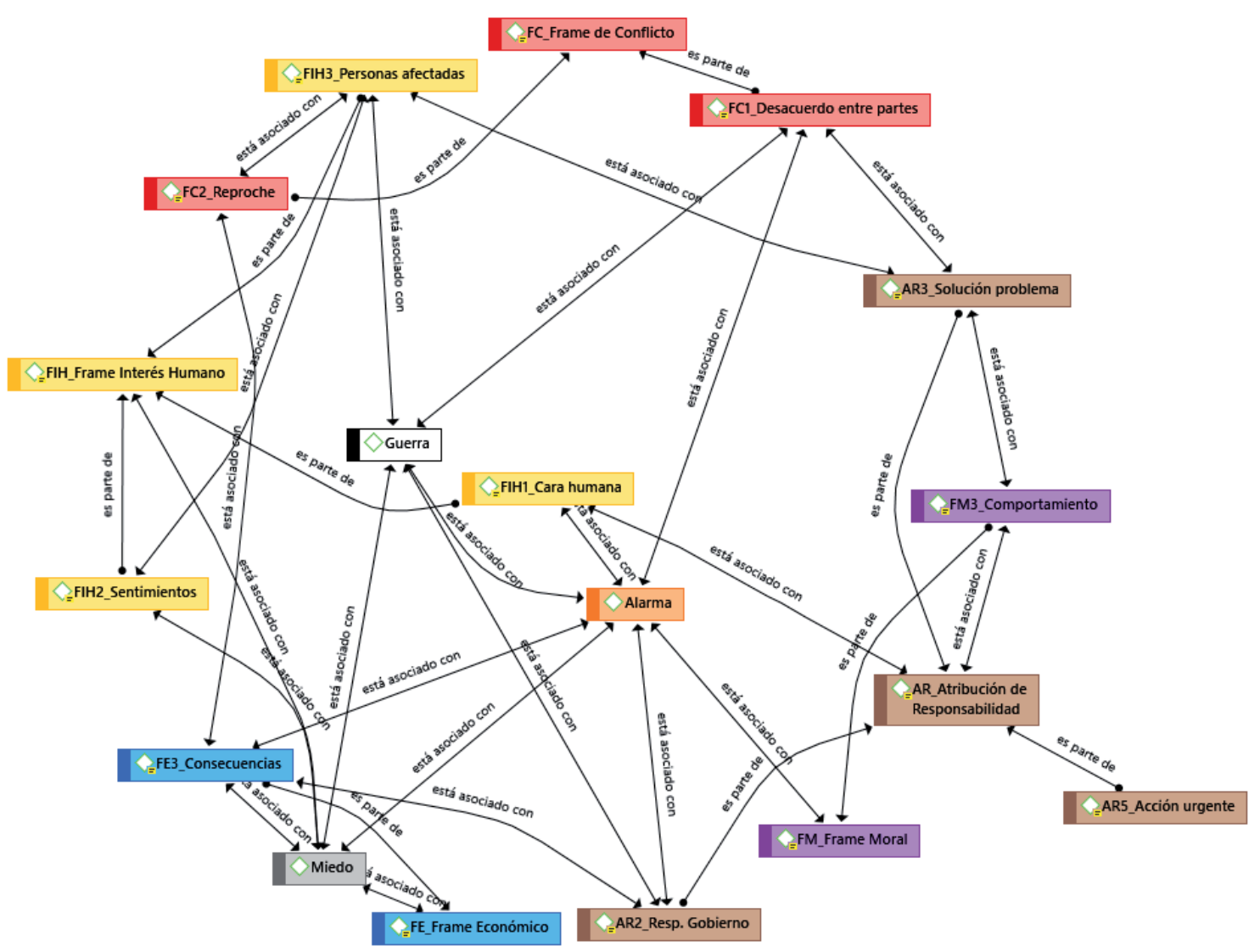

Figura 12. Red de relaciones de la categoría "alarma" Fuente: elaboración propia.

Las correlaciones de la red "alarma" vemos cómo tienen asociación directa con "miedo", "guerra" y con cada uno de los cinco frames en general o con alguna de sus preguntas específicas.

Red de relaciones "miedo" 


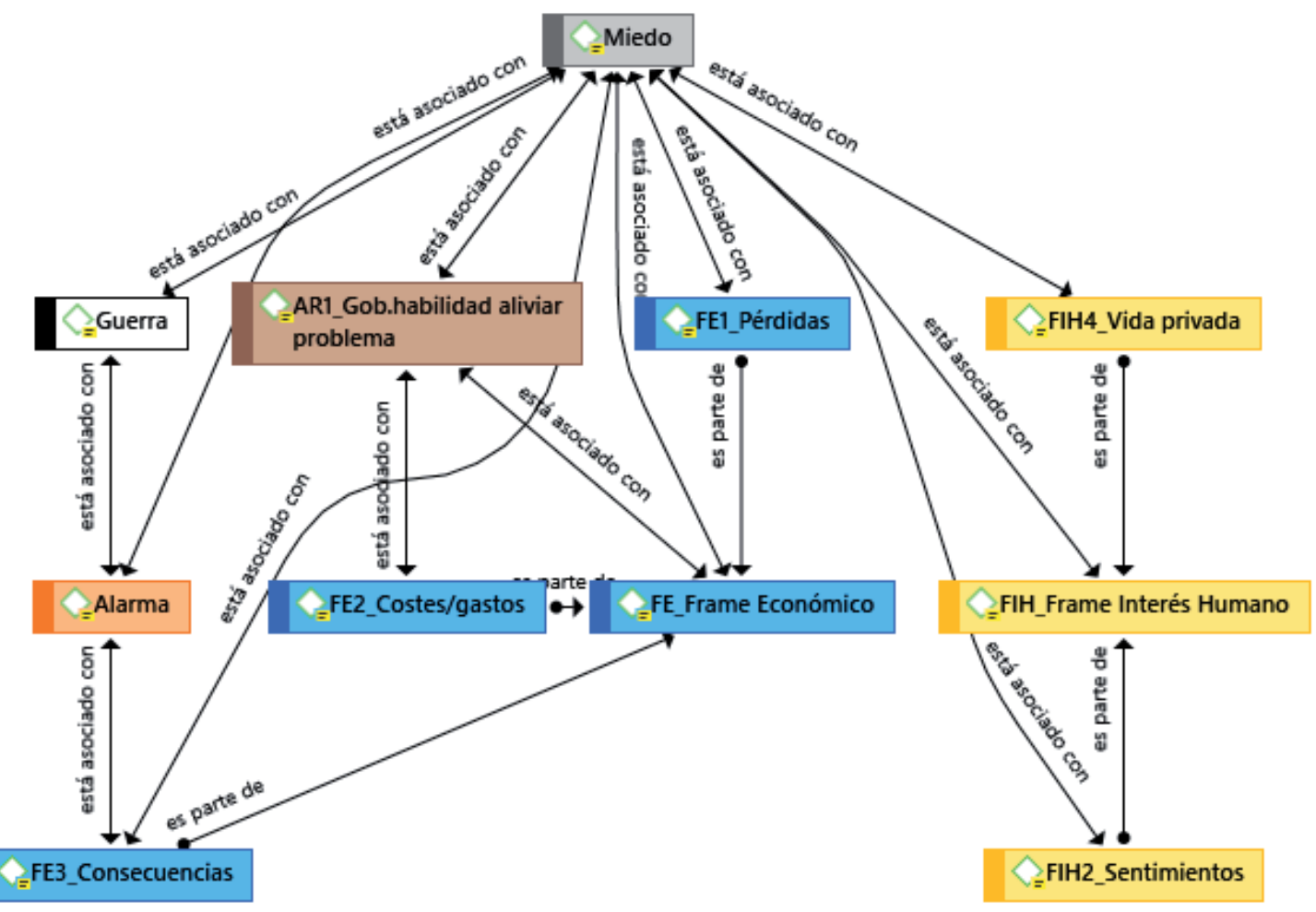

Figura 13. Red de relaciones de la categoría "miedo"

Fuente: elaboración propia.

En esta última red referida al "miedo" vemos como su relación directa la hace con la categorización "guerra" y "alarma" así como con los encuadres, "económico" e "interés humano", atribuyendo al gobierno la habilidad/responsabilidad para solucionar el problema.

Al realizar el análisis de las redes, se corrobora la relación del encuadre "conflicto" con la alarma, el miedo y la guerra. Es decir, si realizamos un análisis a través de extractos concretos categorizados en alarma, miedo y guerra, si se da una alta presencia de ellos.

\section{DISCUSIÓN Y CONCLUSIONES}

El objetivo principal de esta investigación ha sido conocer cómo ha sido el tratamiento mediático que ha hecho la prensa de las noticias de la Covid-19 antes del estado de alarma. Para ello se han identificado los encuadres noticiosos más utilizados y, en particular, se ha analizado en mayor profundidad cómo ha sido el encuadre del conflicto.

Los resultados obtenidos concuerdan parcialmente con los estudios previos, que indican que la comunicación de la Covid-19 en los medios españoles se caracteriza por un cierto alarmismo, apelación al miedo, usando una narrativa belicista y sensacionalista. La concordancia resulta parcial ya que si atendemos cuantitativamente a los resultados obtenidos con respecto al framing utilizado, no queda reflejado que las publicaciones analizadas conlleven una mirada conflictiva en sus narraciones al ser el encuadre "conflicto" el que muestra menos presencia entre todas ellas, por lo que la hipótesis de partida no se confirmó. No obstante, en el análisis intracategoría, observamos como este encuadre sí tiene una relación directa con el uso de narrativas bélicas y alarmistas, que junto a la apelación del miedo, se constituyen en los 
recursos más utilizados dentro de este encuadre, a la vez que permiten establecer relaciones directas con los otros encuadres.

La presencia de este tipo de lenguaje encuentra coincidencia con otras investigaciones en cuanto al uso de lenguaje bélico (Sabucedo et al., 2020), el alarmismo (Costa-Sánchez y López García, 2020), y la percepción generalizada de la población de que se están enfocando las comunicaciones de la epidemia con un tinte sensacionalista (Masip et al., 2020). De hecho, en relación a los encuadres mediáticos más utilizados, se concluye que los que más protagonismo adquieren son el de "interés humano", seguido a la par por "atribución de responsabilidades" y "económico". Estos encuadres apuntan que las publicaciones analizadas hasta la fecha indicada, hacían alusión en su mayor porcentaje a historias de carácter personalista, con el objetivo, suponemos, de trasladar al conjunto de lectores el matiz emocional de las noticias narradas, como estrategia de captación de audiencia.

Por otro lado, a través del encuadre de "atribución de responsabilidades", pensamos que es otro mecanismo que tiende a emplear metáforas belicistas al identificarse que en toda la gestión de la pandemia existen actores que no han desempeñado correctamente su labor o que no han gestionado de forma adecuada la epidemia.

En el caso del encuadre "conflicto" y como ya se ha comentado, cuenta tan solo con el $22.60 \%$ de presencia, siendo el menos representado en la muestra de noticias, lo que supone la nota discordante con las investigaciones previas no corroborando a nivel cuantitativo la presencia de encuadres que se enmarquen en la conflictividad. Es probable que la tendencia observada se pueda explicar por el momento temporal en que se recogió la muestra de noticias, esto es, un par de semanas antes del estado de alarma.

Por lo tanto, se demuestra que esta perspectiva belicista y alarmista en las noticias de la Covid19 tal y como concluían las investigaciones previas, encuentran en esta investigación su verificación si atendemos al encuadre de "conflicto". Es decir, cada vez que la noticia se narra desde este marco, los recursos narrativos relacionados con el lenguaje belicista, la alarma y el miedo constan de una alta presencia. A su vez, estos conceptos son trasladados hacia el público, generando en él mayores niveles de alarma social (Gil Calvo, 2003) y amplificando el sentimiento de inseguridad (Camacho, 2009), siendo quizás utilizados como factores persuasivos para convencer a la población a hacer lo que se le demanda (Rodríguez Andrés, 2011).

Se concluye por consiguiente que siendo la prensa un medio masivo de comunicación con capacidad de difundir su mensaje a un gran número poblacional, no se encuentran a nivel cuantitativo evidencias de una posición genuinamente alarmista, inserta en el miedo o bélica, más allá del encuadre "conflicto", siendo las cuestiones individuales y personales las más usadas para así generar inquietud al lector a través de historias con alto contenido emocional. Debido a la alta presencia de las notas de prensa con carácter personalista, sí que podemos concluir sin embargo, que a nivel cuantitativo la muestra de noticias se envuelven en un perfil sensacionalista destacando los aspectos más llamativos de las noticias para captar audiencia.

En cuanto a las limitaciones con las que nos hemos encontrado en el estudio, cabe destacar la diferente metodología y formatos a la hora de la recolección de la muestra de noticias. En el caso de El País se recogieron las noticias en su formato digital, mientras que en La Vanguardia y El Periódico se recogieron en formato impreso digitalizado que era la única opción disponible 
para recopilar el material. Esto implicó que estos últimos, en un mismo archivo se encontraban contenidas varias noticias, tanto las seleccionadas en la muestra como otras que nada tenían que ver con el estudio, lo cual, en el caso del análisis del Atlas.ti, ha conllevado más dificultades a la hora de analizar cada noticia.

Otra limitación ha sido la temporalidad escogida para realizar el análisis. Al comenzar esta investigación a principios de marzo la selección de las noticias se limitó a las que había publicadas hasta ese momento, no coincidiendo con el punto álgido de las comunicaciones de la Covid-19, las cuales acontecieron durante los meses de abril y mayo.

Se propone así como futuras líneas de investigación el análisis de las noticias ocurridas durante y después del confinamiento en España. En el primer caso porque al incrementarse el impacto de la epidemia en nuestro país, el prisma desde el que se han podido comunicar los acontecimientos es probable que haya cambiado y que se alcen con el mayor porcentaje de uso otro tipo de encuadres diferentes. En el segundo caso, para analizar desde qué enfoque se realizan en los medios las prescripciones y recomendaciones sanitarias y así conocer la eficacia y el impacto comunicativo que tiene sobre la población.

Además, se sugiere que al análisis de noticias de prensa se añada el análisis de noticias audiovisuales como los telediarios, para de esta manera cubrir los dos grandes medios masivos de generación de noticias, lo cual puede dar una visión más amplia e incluso generar diferencias entre los encuadres de ambos medios de comunicación.

En cuanto a la función de los medios de comunicación, queda claro que se constituyen como un gran agente activo en cualquier tipo de acontecimiento y más aún en aquellos que conlleven consecuencias sanitarias, económicas y sociales como es el caso del Coronavirus. Los medios funcionan como altavoces de gran magnitud que dado su poder de expansión pueden ejercer un papel pacificador, aséptico o intensificador de cualquier tipo de conflicto social, activando u opacando la intervención de los agentes sociales que pueden intervenir en cualquier tipo de situación conflictiva. Se recomienda por ello que los medios comuniquen teniendo en cuenta su gran poder de movilización o desmovilización para no intensificar situaciones que de por sí ya generan desacuerdo o conflicto.

\section{Referencias}

Ajuntament de Barcelona. (2019). Enquesta de serveis municipals 2019. https://w10.bcn.cat/APPS/riswestudis/documentacio.do?reqCode=mostrarlmatge\&idDoc=107 87

Altheide, D. L. (2002). Creating fear: News and the construction of crisis. Transaction Publishers.

Anguera, M. T., Blanco-Villaseñor, A., Losada, J. L., Sanchez-Algarra, P. \& Onwuegbuzie, A. J. (2018). Revisiting the difference between mixed methods and multimethods: Is it all in the name? Quality \& Quantity, 52 (6), 2757-2770. https://doi.org/10.1007/s11135-018-0700-2

Anguera, M. T., Portell, M., Chac'on-Moscoso, S. \& Sanduvete-Chaves, S. (2018). Indirect observation in everyday context: Concepts and methodological guidelines within a mixed methods framework. Frontiers in Psychology, 9 (13). https://doi.org/10.3389/fpsyg.2018.00013

Ardèvol-Abreu, A. (2015). Framing o teoría del encuadre en comunicación. orígenes, desarrollo y panorama actual en España. Revista latina de comunicación social, (70), 423-450. https://doi.org/10.4185/RLCS-2015-1053 
Argiñano, J. L., \& Bilbao, U. G. (2020). Análisis de los titulares y las fotografías de portada en España en el contexto de la crisis del coronavirus: protagonistas, frames y lenguaje bélico. Revista de Comunicación y Salud, 10(2), 1-23. https://doi.org/10.35669/rcys.2020.10(2).1-23

Beck, U. (1998). La sociedad del riesgo: Hacia una nueva modernidad. Paidós

Boster, F. J. \& Mongeau, P. (1984). Fear-arousing persuasive messages. Annals of the International communication Association, 8 (1), 330-375. https://doi.org/10.1080/23808985.1984.11678581

Busquets Duran, J. \& Medina Cambrón, A. (2013). Sociologia de la comunicació. UOC.

Camacho Markina, I. (2009). Pánico infundado. Tratamiento del brote de "gripe a" en la prensa española. Actas I Congreso Internacional Latina de Comunicación Social, (64), 827-843. http://www.revistalatinacs.org/09/Sociedad/actas/19idoia.pdf

Casero-Ripollés, A. (2020). Impact of covid-19 on the media system. communicative and democratic consequences of news consumption during the outbreak. El profesional de la información, 29 (2). https://doi.org/10.3145/epi.2020.mar.23

Chomsky, N. \& Herman, E. (1990). Los guardianes de la libertad. Grijalbo.

Costa-Sánchez, C. \& Lopez-García, X. (2020). Comunicación y crisis del coronavirus en España. primeras lecciones. El profesional de la información (EPI), $29 \quad$ (3). https://doi.org/10.3145/epi.2020.may.04

Council, N. R. (1989). Improving risk communication. https://doi.org/10.17226/1189

De Vreese, C. H. (2004). The effects of strategic news on political cynicism, issue evaluations, and policy support: A two-wave experiment. Mass Communication \& Society, 7 (2), 191-214. https://doi.org/10.1207/s15327825mcs0702_4

De Vreese, C. H. (2005). News framing: Theory and typology. Information design journal \& document design, 13 (1). https://doi.org/10.1075/idjdd.13.1.06vre

De Vreese, C. H., Peter, J. \& Semetko, H. (2001). Framing politics at the launch of the euro: A crossnational comparative study of frames in the news. Political communication, 18 (2), 107-122. https://doi.org/10.1080/105846001750322934

Entman, R. M. (1993). Framing: Toward clarification of a fractured paradigm. Journal of Communication, 43 (4), 51-58. https://doi.org/10.1111/j.1460-2466.1993.tb01304.x

García Perdomo, V. M. \& Guti'errez Coba, L. M. (2011). Manual de géneros periodísticos (2.a ed.). Universidad de la Sabana. http://hdl.handle.net/10818/27786

Gil Calvo, E. (2003). El miedo es el mensaje: Riesgo, incertidumbre y medios de comunicación. Alianza.

González, R. B., y Cambra, U. C. (2015). El virus del Ébola: análisis de su comunicación de crisis en España. Opción, 31(4), 67-86.

Hallin, D., Briggs, C., Martini Briggs, C., Spinelli, H. \& Sy, A. (2020). Mediatización de las epidemias: La cobertura sobre la pandemia de la gripe a $(\mathrm{h} 1 \mathrm{n} 1)$ de 2009 en argentina, estados unidos y venezuela. Comunicación y sociedad, (9), 1-24. https://doi.org/10.32870/cys.v2020.7207

Igartua, J. J., Cheng, L., Moral, F., Fernández, I., Frutos, F. J., Gómez-Isla, J. \& Otero, J. A. (2008). Encuadrar la inmigración en las noticias y sus efectos socio-cognitivos. Palabra Clave, 11 (1), 87107. https://www.redalyc.org/articulo.oa?id=64911108

Igartua, J. J., Muñiiz, C. \& Cheng, L. (2005). La inmigración en la prensa española. aportaciones empíricas y metodológicas desde la teoría del encuadre noticioso. Migraciones. Publicación del Instituto Universitario de Estudios sobre Migraciones, (17), 143-181. https://revistas.comillas.edu/index.php/revistamigraciones/article/view/4220

Kasperson, R. E., Renn, O., Slovic, P., Brown, H. S., Emel, J., Goble, R., . . . Ratick, S. (1988). The social amplification of risk: A conceptual framework. Risk analysis, 8 (2), 177-187. https://doi.org/10.1111/j.1539-6924.1988.tb01168.x 
Lewison, G. (2008). The reporting of the risk from severe acute respiratory syndrome (sars) in the news media, 2003-2004. Health, risk and society, 10 (3), 241-262. https://doi.org/10.1080/13698570802160962

Lorente, J.-I. (2010). H1n1. virus, discurso del riesgo y gestión mediática de la alarma sanitaria. Comunicación y desarrollo en la era digital. II Congreso Internacional de la Asociación Española de Investigadores de la Comunicación (AE-IC). http://fama2.us.es/fco/congresoaeic/37.pdf

Masip, P., Aran-Ramspott, S., Ruiz-Caballero, C., Suau, J., Almenar, E. \& Puertas-Graell, D. (2020). Consumo informativo y cobertura mediática durante el confinamiento por el covid-19: Sobreinformación, sesgo ideológico y sensacionalismo. El profesional de la información (EPI), 29 (3). https://doi.org/10.3145/epi.2020.may.12

Miles, M. B. \& Huberman, A. M. (1994). Qualitative data analysis: An expanded sourcebook (2.a ed.) S. Publications. https://vivauniversity.files.wordpress.com/2013/11/milesandhuberman1994.pdf

Monjas Eleta, M. \& Gil-Torres, A. (2017). Comunicación institucional y tratamiento periodístico de la crisis del Ébola en España entre el 6 y el 8 de octubre de 2014. Revista de Comunicación, 16 (1), 97-121. https://doi.org/10.26441/RC16.1-2017-A5

Muñiz Muriel, C. (2007). Encuadres noticiosos e inmigración: Del análisis de los contenidos al estudio de los efectos mediáticos (Tesis doctoral, Universidad de Salamanca)

Organización Mundial de la Salud (OMS). (2018). Comunicación de riesgos en emergencias de salud pública: directrices de la OMS sobre políticas y prácticas para la comunicación de riesgos en emergencias (CRE)

Quarantelli, E. L. (2002). The role of the mass communication system in natural and technological disasters and possible extrapolation to terrorism situations. Risk Management, 4 (4), 7-21. https://doi.org/10.1057/palgrave.rm.8240130

Rey, G. \& Rincón, O. (2008). Los cuentos mediáticos del miedo. Urvio. Revista Latino-americana de Seguridad Ciudadana, (5), 34-45. https://doi.org/10.17141/urvio.5.2008.1093

Rodríguez-Andrés, R. (2011). La efectividad del uso del miedo como factor persuasivo en la comunicación de riesgos en las crisis sanitarias. Revista de Comunicación y Salud, 1 (2), 33-46. https://doi.org/10.35669/revistadecomunicacionysalud.2011.1(2).33-46

Sabucedo, J. M., Alzate, M. \& Hur, D. (2020). Covid-19 and the metaphor of war (covid19 y la metáfora de la guerra). International Journal of Social Psychology, 4-6. https://doi.org/10.1080/02134748.2020.1783840

Sandman, P. (1994). Mass media and environmental risk: Seven principles. RISK: Health, safety and environment, 5 (3), https://scholars.unh.edu/cgi/viewcontent.cgi?article=1198\&context=risk

Semetko, H. A. \& Valkenburg, P. M. (2000). Framing european politics: A content analysis of press and television news. Journal of communication, 50 (2), 93-109. https://doi.org/10.1111/j.14602466.2000.tb02843.x

Shih, T., Wijaya, R. \& Brossard, D. (2008). Media coverage of public health epidemics: Linking framing and issue attention cycle toward an integrated theory of print news coverage of epidemics. $\begin{array}{lllll}\text { Mass Communication } 11 \text { and } & \text { 141-160. }\end{array}$ https://doi.org/10.1080/15205430701668121

Salván, E. J., y Jurado, M. (2015). Los errores de comunicación en la crisis del Ébola. Cuadernos de periodistas, 90 (29), 90-99

Stiff, J. B. \& Mongeau, P. A. (2003). Persuasive communication (2.a ed.). The Guilford Press.

Tausczik, Y., Faasse, K., Pennebaker, J. W. \& Petrie, K. J. (2012). Public anxiety and information seeking following the h1n1 outbreak: Blogs, newspaper articles, and wikipedia visits. Health communication, 27 (2), 179-185. https://doi.org/10.1080/10410236.2011.571759 
Towers, S., Afzal, S., Bernal, G., Bliss, N., Brown, S., Espinoza, B., Jackson, J., Judson-Garcia, J., Khan, M., Lin, M., Mamada, R., Moreno, V., Nazari, F., Okuneye, K., Ross, M., Rodriguez, C., Medlock, J., Ebert, David., y Castillo-Chavez, C. (2015). Mass media and the contagion of fear: The case of Ébola in america. PLOS one, 10 (6). https://doi.org/10.1371/journal.pone.0129179

Westlund, O. \& Ghersetti, M. (2015). Modelling news media use: Positing and applying the gc/mc model to the analysis of media use in everyday life and crisis situations. Journalism studies, 16 (2), 133-151. https://doi.org/10.1080/1461670X.2013.868139

Wolton, D. (2004). La otra mundialización: Los desafíos de la cohabitación cultural global. Gedisa

\section{Semblanza de las autoras}

Diana Gómez Martínez: Socióloga titulada por la Universidad de Salamanca en el año 2015. Máster en Mediación de Conflictos por la Universidad de Barcelona en el 2020. Interesada en los procesos comunicativos y en cómo estos afectan a las relaciones y realidades sociales. Con una perspectiva holística y social, ha trabajado en el ámbito de la acción social como agente de intervención mediador en el espacio público, generando así una experiencia directa sobre el terreno, para luego pasar al ámbito de la investigación. Abordaje metodológico e investigador enfocado en la creación de nuevo conocimiento con el objetivo de incidir en la mejora de la realidad social y sus procesos particulares.

Angela Castrechini: Psicóloga y Profesora Contratada Doctor en la Facultad de Psicología de la Universidad de Barcelona (UB). Imparte docencia en el Grado en Psicología, así como en los Másters Oficiales en Intervención Psicosocial (MIPS) y en el de Mediación de Conflictos (MOMED). Forma parte del Grupo de Investigación en Psicología Social, Ambiental y Organizacional, PsicoSAO (2017SGR564). Sus áreas de investigación se centran en temas sociales y ambientales como la inseguridad ciudadana, el espacio público, la sostenibilidad y el cambio climático, con un abordaje metodológico centrado en los medios de comunicación social. Ha participado en diferentes proyectos nacionales de investigación y publicado numerosos artículos en revistas y capítulos de libros. 